\title{
Mapping Flood Vulnerability arising from Land use/Land covers Change along River Kaduna, Kaduna State, Nigeria
}

\author{
${ }^{1}$ Ejenma, E., ${ }^{2}$ Sunday, V.N., ${ }^{3}$ Okeke,O., ${ }^{1}$ Eluwah, A.N. and ${ }^{4}$ Onwuchekwa, I.S. \\ ${ }^{I}$ Federal College of Agriculture, Ishiagu, Ebonyi State, Nigeria. \\ ${ }^{2}$ Geography/Environmental Management, University of Port Harcourt, Choba, Port Harcourt, Nigeria. \\ ${ }_{3}^{3}$ Department of Mathematics, Osun State University, Oshogbo, Osun State, Nigeria. \\ ${ }^{4}$ Department of Geography \& Planning, Abia State University, Uturu, Nigeria.
}

\begin{abstract}
This study attempted to assess the spatial impact of river Kaduna flooding of Kaduna South LGA on the surrounding areas using High Resolution Satellite Imagery. A Digital Elevation Model (DEM) was developed with Arc. GIS.10 version to identify flood prone areas along the middle course of the river. A flow accumulation model was created using the DEM and was reclassified into very high risk, high risk, moderate risk, low risk and very low risk zones using equal interval of separation based on elevation. This was overlaid on the map of the settlement extracted from land use/land cover classification of 1990, 2006 and 2010 landsat ETM+ images using ENVI version 4.7 to produce a vulnerability map of the area. The result of the analysis shows that about $30 \%$ equivalent to $17.76 \mathrm{~km}^{2}$ of $59.03 \mathrm{~km}^{2}$ is at very high risk to flood and the remaining $70 \%$ is either moderate or at low risk. It was shown that a flood map can be effectively used in public enlightenment, disaster response planning and flood risk management. This study demonstrated the contribution of geospatial methods in mitigating and monitoring the effects of flooding along river Kaduna and environs.
\end{abstract}

Keywords: land use/land cover, river Kaduna, river flooding, geospatial, disaster.

\section{Introduction}

Floods are the most devastating natural hazard affecting the social and economic aspects of population (Hewitt and Burton, 1971) and claiming more lives than any other natural phenomenon. The frequency with which flood occurs is increasing in many regions of the world with no restriction to the boundary, climate and geo-political zones. Flooding is normally severe in flood plains which are regions of a valley floor located in either side of a river channel that is full of sediments deposited by the river that flows through the surface of land. Flood plains along big rivers are one of the most productive and valuable environments on the surface of the earth that provide abundant ecosystems and human services (Harun, 2009).

Flood plains are a vital part of the river or stream ecosystem. They are important because, they act as flood buffers, water filters and are major centres of biological life in the river or stream ecosystem. According to Goel et al, (2005), floodplain is a relatively smooth land bordering a stream and overflows at a time of high water. Flood plain encroachment has seriously increased flood risk and damage potentials, especially of settlement floods due to heavy socio-economic infrastructural development on these floodplains. It increases flood elevation and flow velocities, flood change patterns and the area of flood inundation. It also results in a loss of stored volume of flood water which in turn increases the downstream flood peaks that then exacerbates flooding and erosion.

Integration of remote sensing and geographic information system (GIS) provides a very effective means of delineating such areas at risk and for communicating this to decision-makers, emergency response teams and the general public (Ojigi and Shaba, 2012). The use of this new technique captures the real topography in longitudinal cross-section and generates a 3D visualization of the study area. The recent increase in settlement flooding and geometric increases in the number of causalities, death and loss of property/critical infrastructure have renewed the call for intensive research aimed toward building applicable models, workable mitigation methods and preferably sustainable early warning and preventive mechanisms. In addition, there is also need for comprehensive vulnerability analysis, spatio-temporal multi-data integration and synthesis, geospatial and socio-economic analysis.

This paper therefore attempts to address vulnerability to flooding arising from land use/land cover dynamics around river Kaduna using these techniques.

\section{The Problem}

Flood plain encroachment originates from different levels of human environmental systems. In the distant past, people were attracted to flood plains for access to water supply, transportation, power development and settlement particularly for low income families (Ojigi and Shaba, 2012). Issues of development and poverty 
have led local communities and more people to live in areas vulnerable to flooding(Rosenberg, 2008). Another factor that drives encroachment is occupation. Most of the people who live in areas vulnerable to flooding are fishermen who earn their livelihoods through fishing. It is common with riverine village dwellers. Land use decision typically occurs at the local level and is based on local standards. Proposed encroachments are routinely permitted, even in areas prone to flood damage and even if those developments exacerbate the vulnerability of flooding to adjacent properties. Encroachments into river flooding plains often result in landowners seeking to protect those properties using structural measures and channelization practices. Clearing the floodplain for agriculture permits a progressively higher percentage of large flood discharge to be carried by the flood plain. Some parts of the flood plain are eroded and other parts are built up by deposition of coarse sediments, while the channel capacity of the river is gradually reduced. Satellite remote sensing, helps in monitoring and understanding the process of flood plain encroachment. It is on this basis that this paper is premised.

\section{Study Area}

The study was limited to Unguwan rimi amd environs in Kaduna South LGA of Kaduna State with its headquarters in Makera town. Kaduna South has an area of $59 \mathrm{~km}^{2}$ and a population of 402,390 in the 2006 census. It lies on latitude $10^{\circ} 26^{\circ} \mathrm{N}$ and $10^{\circ} 32^{\circ} \mathrm{N}$ of the equator and longitudes $7^{\circ} 24^{\circ} \mathrm{E}$ and $7^{\circ} 28^{\circ} \mathrm{E}$ of the Greenwich meridian and lies on the banks of river Kaduna. The area is drained by the river Kaduna which is a tributary of river Niger, passing through Kaduna city which is one of the major trade centres in Nigeria (Fig.1). flood disasters that have inundated large areas along river Kaduna flood plain claimed several lives and properties, hence the need for an efficient flood hazard mapping of the areas adjacent to the river course in order to adequately mitigate the damage incurred the next time there is a massive overflow from the river and also curb the current rapid expansion of settlements into the low-lying flood plains by establishing appropriate landuse legislations is urgent.

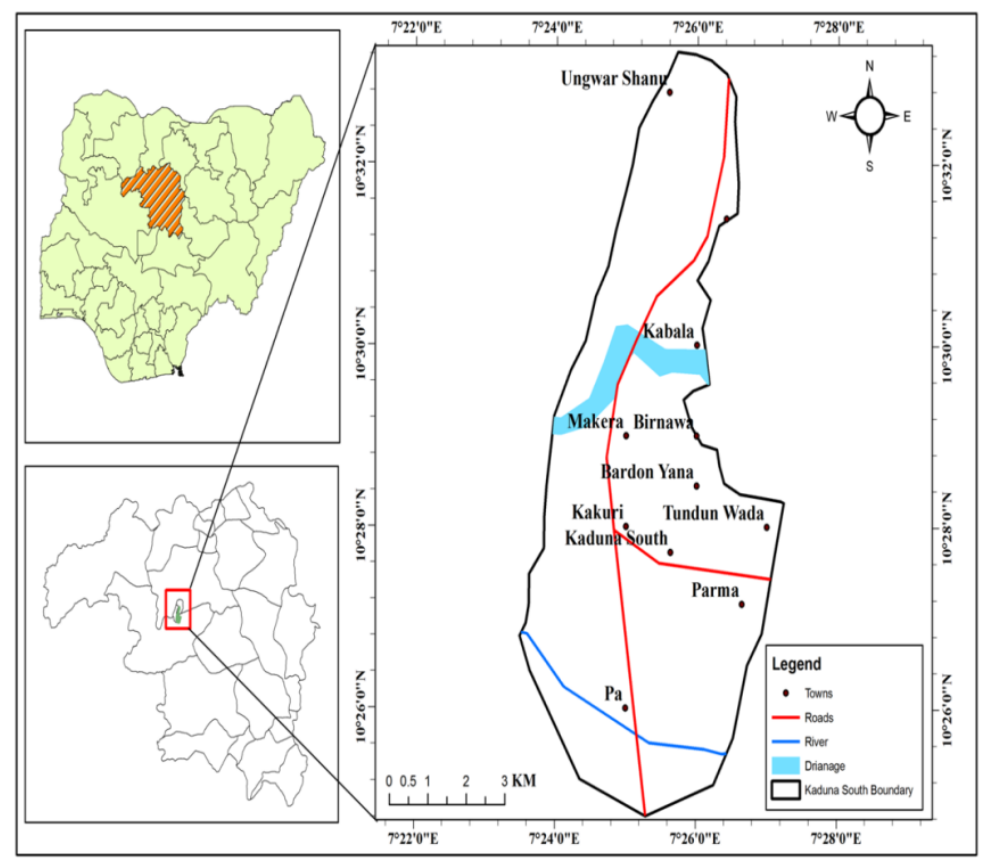

Fig.1: Study Area.

\section{Methodology}

The study focused only on flood vulnerability due to land use/land cover changes in Kaduna South through high resolution imagery. A Digital Elevation Model (DEM) was developed with Arc GIS 9.3 version to identify flood prone areas along the middle course of the river. The DEM was reclassified into high risk, moderate risk and low risk zones using equal interval of separation based on elevation. Then the vulnerability map of the area was produced.

Using the ENVI 4.7 version software, the images were imported one after the other using the Geo-tiff format. After sharpening, the bands of interest were selected and stacked. From the stack, a colour composite of bands 4,3 and 2 was generated and resampled in a new display. Further band 4 of the land sat image was loaded for red band, 3 and 2 were loaded for green and blue respectively. The band combination has been regarded as efficient and adequate when using landsat image data for flood vulnerability studies in relation to land use/land 
cover mostly because it has to do with vegetation, farmland, water body, bare surfaces and built-up areas (Ojigi, 2010). After the colour composite, the image was subset using the Region of Interest (RO1) vector frame created in Arc. GIS 9.3 version imported into the ENVI 4.7 environment as shape file, with this, ROI of this study (Kaduna South) was delineated from the Kaduna State administrative map. Further, the subset colour composite image was classified using maximum likelihood classification and defined land use/land cover class (table.1). Post classification operations including confused matrix using ground truth ROI (a confusion matrix value of $94.2 \%$ was achieved for the classification), sieve class clump class, majority/minority analysis, segmentation and classification to vector were done. The image was then imported to Arc. GIS 9.3 version where it was vectorised and the area extent of flooded area and other land use/land cover classes determined after the post classification operations.

On vulnerability, the flood vulnerable area boundary was extracted from the DEM (fig.3) which was generated from the digitized contours of the Shuttle Radar Topography Mission (SRTM). River Kaduna was also digitized from the administrative map and overlaid on the flood vulnerable areas map. Triangular Irregular Networks (TIN) was also generated from the contours extracted from these SRTM. The criterion used for delineating the flood vulnerable areas is height (elevation) achieved using the DEM. A combination of the LANDSAT ETM + imagery and SRTM was used to establish flood extent for Kaduna South area, the Kaduna river flooding and the fluvial flood vulnerability mapping of the area. The settlement map was used to co-locate flooded areas with settlements. The study area was thereafter categorized into very highly vulnerable, highly vulnerable, moderately vulnerable, lowly vulnerable and very lowly vulnerable to river flood disaster and risk, using ground elevation, flood history and nearness (buffer) to river channel as criterion. Flood risk map was produced using the exposure of the vulnerable area to flood hazards. A flow accumulation model was also created using the DEM and this was overlaid on the map of the area to produce a vulnerability map.

\section{Results and Discussion}

Table 1: Landsat ETM + images for land use/land cover classification (1990-2010)

Land use/land cover 1990 2006

2010

$\begin{array}{lllllll} & \text { Area }\left(\mathrm{km}^{2}\right) & \% & \text { Area }\left(\mathrm{km}^{2}\right) & \% & \text { Area }\left(\mathrm{km}^{2}\right) & \% \\ \text { Built - up area } & 8.95 & 14.97 & 19.57 & 31.35 & 33.41 & 56.69 \\ \text { Bare land } & 13.05 & 21.85 & 14.65 & 28.2 & 16.65 & 15.9 \\ \text { Vegetation } & 28.44 & 47.6 & 15.34 & 25.85 & 12.9 & 21.81 \\ \text { Water body } & 9.31 & 15.58 & 9.66 & 14.6 & 3.3 & 5.6 \\ \text { Total } & 59.75 & 100 & 59.22 & 100 & 59.03 & 100 \\ \text { Kappa coefficient } & 0.893 & & 0.931 & & 0.967 & \\ \text { verall accuracy \% } & 90.39 & & 94.23 & & 97.22\end{array}$

Source: Authors'fieldwork.

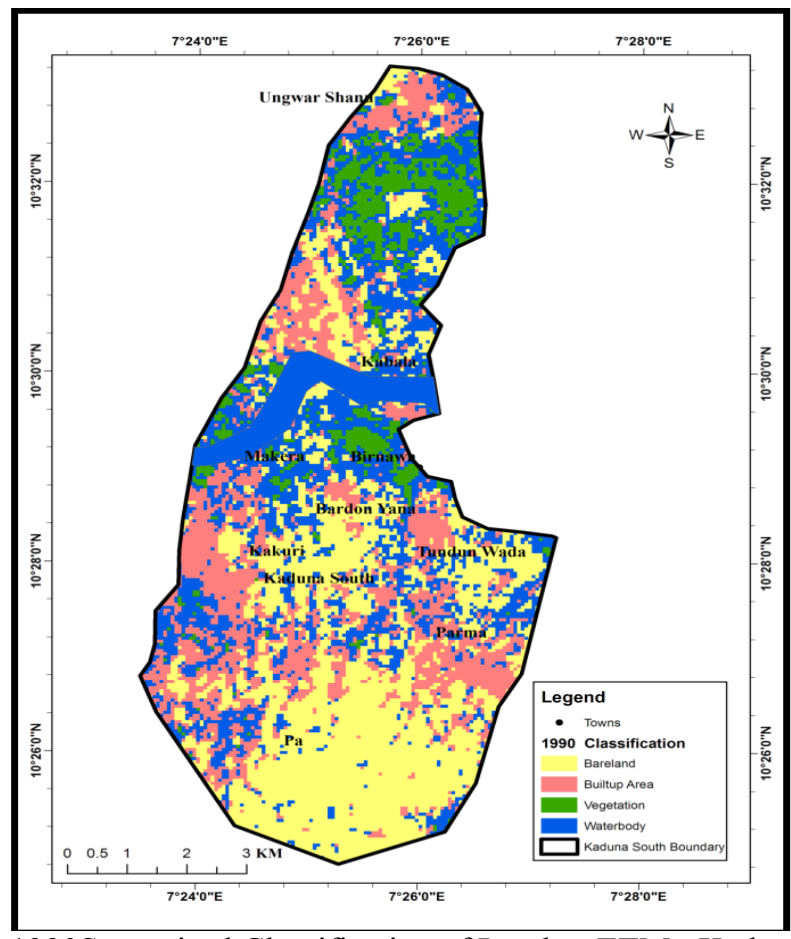

Fig. 2: 1990Supervised Classification of Landsat ETM+ Kaduna South 
The figures (2, 3 and 4) showed the results of the various processes itemized for the thematic mapping $(\mathrm{ETM}+)$ image data sets. Also table 1 showed the statistical results of the classification of the data set. From these figures, there is a remarkable difference in the classification as evidenced in table 1. In comparism, figures 2,3 and 4 and table 1, built up area covered $8.95 \mathrm{~km}^{2}(14.97 \%)$ in 2006 and further decreased to $3.3 \mathrm{~km}^{2}(5.6 \%)$ in 2010 .

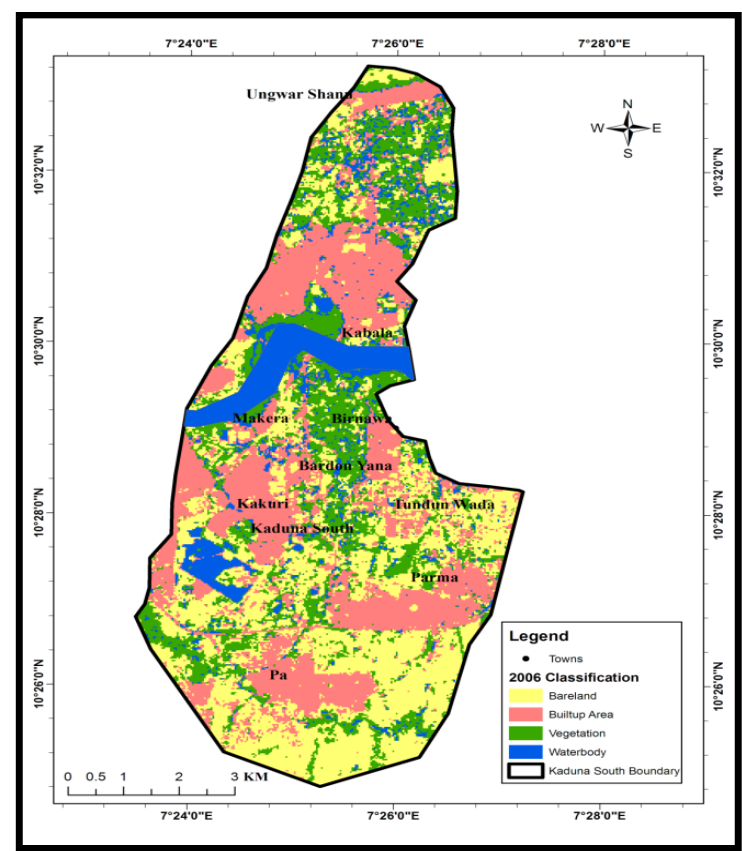

Fig.3: 2006 Supervised Classification of Landsat ETM+ Kaduna South

This was probably as a result of massive encroachment and farming activities and built up areas. Table 1 was used to quantify and model the land cover change based on the land useclassifications.

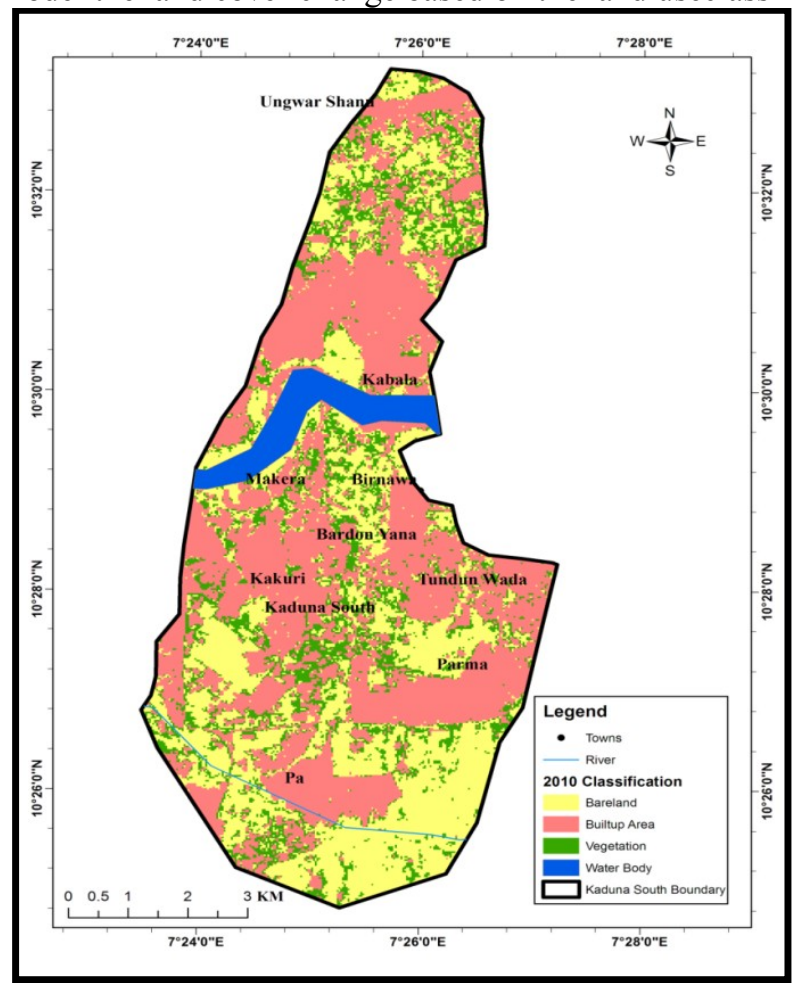

Fig.4: 2010 Supervised Classification of Landsat ETM+ Kaduna South

Figure 5 shows the areas vulnerability to flood hazard and risk of Kaduna South. The areas on terrain elevations of $0.583 \mathrm{~m}$ were categorized as very highly vulnerable, while areas on terrain elevations of $583-607 \mathrm{~m}$ and $607 \mathrm{~m}$ above - were categorized as medium, or moderately vulnerable, lowly and very lowly vulnerable 
areas respectively (figs. 5 and 6). Thus, locations of ground elevations of $607 \mathrm{~m}$ above mean sea level (AMSC) were considered as safe ground for evacuation and establishment of emergency relief camps during flood events. This was based on the field assessment, terrain analysis, the flood water heights of $12.5-15 \mathrm{~m}$ above natural river level, socio-economic and environmental processes in the area.

Creation of flood vulnerability map which was based on DEM of the middle course of the river is as shown on figures 5 and 6 . It should be noted that the areas used are the areas at risk from river Kaduna floods as identified by Jeb and Aggarwal (2008). Using the elevation of the area, flow accumulation analysis was carried out to discover the natural drainage pattern of the area. The light coloured portions show catchments that flood waters and surface run-off will accumulate which will serve as reservoirs for flood waters. The regions within the red area (fig.5) are very highly vulnerable to flood than the areas in the yellow which are lowly vulnerable to flood than the light blue area and blue areas which are moderately vulnerable, lowly and very lowly vulnerable to flood respectively.

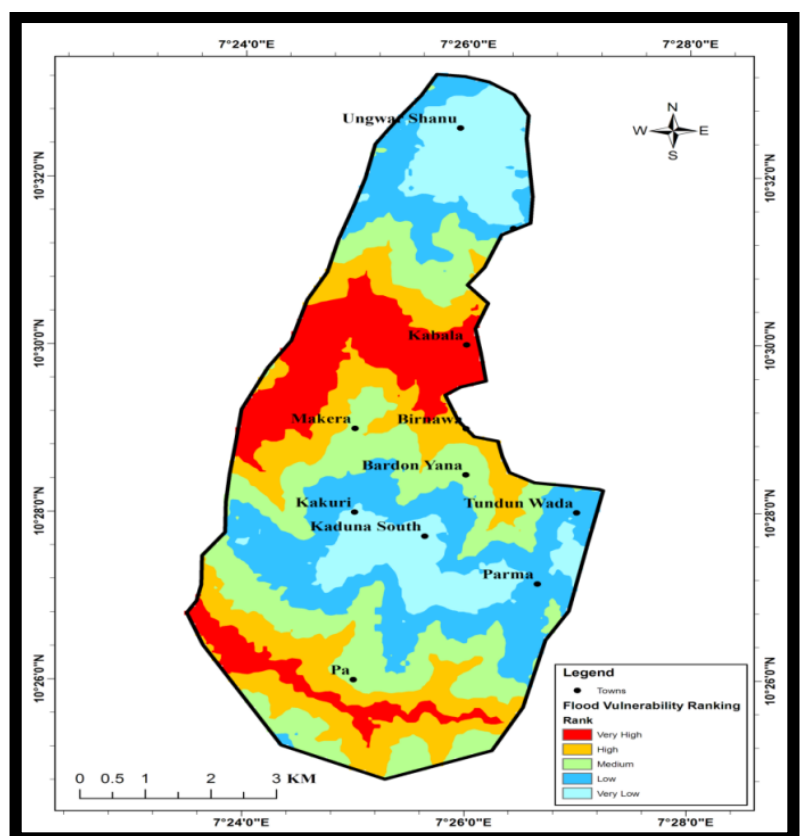

Figure 5: Flood Vulnerability map of the Area

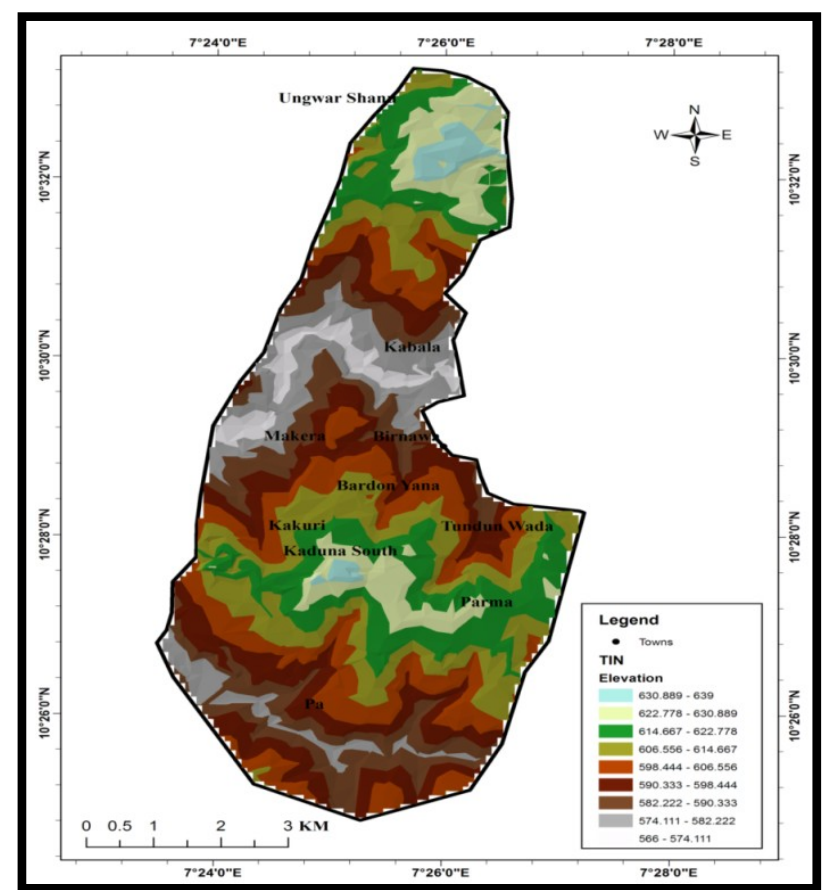

Figure 6: Triangular Irregular Network (TIN) of the study area. 


\section{Conclusions}

Flooding may not be completely avoided as long as physical development extends to river channels. However with effective flood prevention programmes, damages from severe flooding can be reduced. Mitigation is hence the cornerstone of emergency management as rightly observed by Olorukoba (2009). The non-structural methods of mitigation of flood hazards are often less expensive as compared to structural ones (dams and dikes). Among the non-structural methods, modern flood forecasting and real-time data collection system have become the practice in countries prone to flood hazards. In Nigeria, flood management measures including planning, observation and warning are generally lacking and interventions are mostly reactive in the form of post flood emergency measures (preventive or precautionary) put in place by the local authorities. The study finally concludes that flood plain settlements are ancestral heritage, hence cannot be abandoned for fear of flood.

\section{References}

[1]. Goel, N. K.; Than, H.H. and Arya, D.S (2005). Flood hazard mapping in lower part of Chindwin river basin, Myammar. International conference on innovation advances and implementation of flood forecasting technology, Tromso, Norway.

[2]. Harun, S. (2009). Remote sensing techniques for flood mapping in Bangladesh, Clark University, Bangladesh.

[3]. Hewitt, K. and Burton, I. (1971). The hazardonsness of a place: a regional geology of damaging events. University of Toronto, dept. of geography research publication 5, p.154.

[4]. Jeb, D. N. and Aggarwal, S.P. (2008). Flood inundation hazard modeling of the river Kaduna using remote sensing and geographic information systems. Journal of applied sciences research. pg. 182-183.

[5]. Ojigi, M.C. (2010). Flood hazard and risk mapping of Birni Kebbi and environs using geospatial techniques. Journal of geographic information science vol. 1 no. 1 .

[6]. Ojigi, M.C. and Shaba, A.H. (2012). Integration of Synthetic Aperture Radar (SAR) imagery and Digital Terrain Model for determining flood water threshold in Sokoto and environs, Nigeria. Proceedings of the Geo-information society of Nigeria and Nigerian Cartographic Association (NCA) joint annual workshop/conference held at Regional Centre for Training in Aerospace Surveys (RECTAS) Obafemi Awolowo University, Ile Ife, $19^{\text {th }}-22^{\text {nd }}$ Nov. 2012. pg $291-303$.

[7]. Olorukoba, Y.A. (2009). Flood vulnerability analysis around Asa river in Ilorin using GIS. Unpublished MGIS dissertation, dept. of Geography \& Environmental Management, University of Ilorin.

[8]. Rosenberg, M. (2008). Floods and flooding; an overview of floods and flooding.about.com.guide geography. Retrieved 14/01/2012. 